\title{
КРИТИКО-БИБЛИОГРАФИЧЕСКИЙ ОТДЕЛ
}

Reviews

\author{
T. В. Горячева, О. М. Сергеева \\ Институт русского языка им. В. В. Виноградова РАН \\ (Россия, Москва) \\ etymol@mail.ru
}

\section{Рец.: ДОБРОДОМОВ, ИГОРЬ ГЕОРГИЕВИЧ. ИЗБРАННЫЕ ТРУДЫ ПО ЭТИМОЛОГИИ И ЛЕКСИКОЛОГИИ. - М.: МПГУ, 2015. — 460 c. — ISBN 978-5-4263-0284-6}

Рецензия представляет научное издание Добродомов И.Г. Избранные труды по этимологии и лексикологии, вышедшее в конце 2015 г.

Ключевые слова: лексика, слово, фразеологизм, апеллятив, топоним, заимствование, арготизм, диалектное.

В книге представлены труды доктора филологических наук, профессора И.Г. Добродомова, в которых решаются проблемы этимологии и ономастики, исторической лексикологии, лингвистического источниковедения, истории материальной культуры, этнографии и этнологии. Выяснено происхождение и описана история функционирования слов и фразеологизмов русского и иных языков, определены и разработаны принципы языковых заимствований, наиболее достоверно отграничены тюркизмы в русском и славянских языках от заимствований из других языков Евразии.

Приведем алфавитный индекс исследуемых слов и явлений с указаниями страниц данного научного издания: аксиос(bl) 394-404; Анбал / Амбал (антропоним), амбал (апеллятив) 279-296; арготические глаголы на -ма- 358-362; аутсайдер 101-102; б(ъ)дынъ / одын 329-333; балаган 158-161; баранчук 369-375; батрак 369-375; берёза 226-234; Боняк Шелудивый (антропоним) 11-16; боръ, борове, аки борове, *бърь 143-149; бырсь 134-135; взъефантулить 376-387; водмать 359; вор 110-117; впоглаза 363-368; вполголоса 363-368; вполноги 363-368; вполплеча 363368; вполуха 363-368; гамаши 52-53, 62-64; гапаксы 339; грипn 68; губа 'гриб' 65; деньга 176-180; держать в ежовых рукавицах 187-205; держать в черном теле 187-205; дериватологические признаки 441-453; допьтммать 359; дрофа 39-46; 
дудак 39-46; жемчуг 17-31; жилет 47-48, 67-68; жудь, жуть 150-152; ильиь 137-139; источниковедение и история слова 405-440; йогурm, иогурm, югурт 98101; кадама, кайданы 162-164; казна, казначей 35-38; камасы 52-53; капторга 339-340; квари 68; книга 70-78; Коломна (топоним) 262-278; колчан 118-124; копага 164-165; крикмать 359; кузькина мать 256-261; къметь, къмети 297-310, 405-440; лаударонь = лацциарони 337; лашла = лепила 335-336; люстра 242-246; лягмать 359; ляжмать 359; магазин 32-35; малай 369-375; малахай 48; мантифолия 214-221; мохер, мохеровый 102-103; научмать 359; олух 311-317; паникадило 242-246; парус 61; пистолет, пистоль 69; пищаль 69; погодьмать 358-; порть 'одежда' 153-157; порть 'топор' 153-157; потасовка 222-225; префикс 333-334; призрачные слова 329-338; пърь 'парус' 132-134; реформа орфографии 318-328; рядматься 359; сабля, шабля 181-185, 247; садмать 359; свальматься 359; сижмать, симать 361; сизимать (на-, об-, по-, про-с.) 360, 362; слушмать 359; сморозить 387-394; стерегмать 360; стоймать 359; стрема́, на стрёме 336-337; сундук 66; сюкур, сюкуры 135-137; таракан (от тархан — ложная этимология) 54-60; транжирить 247-255; трещчотка 235-237; Тьмутаракань (топоним) 104-109; урильник, урыльник 334-335; фендрик 214-221; фурстовина 206-213; хлябь 168175; чебак 92-96; чеботы 130; чемерища 214-221; чирики 131-132; чубак 139-141; чулок 65, 128-131; шапка 84-92; шаромыга, широмыга, шармак 341-357; шереширь 185-186; шибболет 454-459; ильк 47-48; этика и этикет 238-241; янтарь 79-83.

Все эти сюжеты были опубликованы за полувековой период творческой деятельности И.Г. Добродомова (Добродомов 1964, 1966, 1967, 1968a, 19686, 1969, 1970a, 1970б, 1970в, 1971a, 1971б, 1971в, 1971г, 1972a, 1972б, 1973a, 1973б, 1974a, 19746, 1975, 1976, 1977, 1978, 1980, 1981, 1983, 1984, 1985a, 19856, 1987a, 1987б, 1987в, 1988а, 1988б, 1988в, 1989, 1991, 1993а, 1993б, 1997, 1998, 2003а, 2003б, 2008, 2009, 2010, 2011a, 2011б, 2013а, 2013б, 2014a, 2014б), а также публикации, выполненные в соавторстве с другими лексикологами (Добродомов, Эккерт 1986; Добродомов, Шаповал 2005; Добродомов, Камчатнов 2014).

Следует высказать слова благодарности всем коллегам и ученикам проф. И.Г. Добродомова, которые взяли на себя тяжелый труд, связанный с подготовкой этого сборника: Дагуровой Д. В., Державиной Е. И., Камчатнову А. М., Камчатновой Ю. Б., Крючковой Л. Л., Латфуллиной Л. Г., Сарапс М.В., Соболевой А.Е., а также студенткам филологического факультета МПГУ Герасимовой А. и Ереминой М. Благодаря их труду лексикологические исследования И.Г. Добродомова стали легко обозримыми и показали всю широту и глубину его таланта.

Особенную ценность представляют статьи, опубликованные ранее в малотиражных сборниках, которые сейчас труднодоступны, а также тексты докладов на всероссийских, межвузовских, научно-практических и международных конференциях, ранее в полном виде не опубликованные.

Особый интерес представляют предложенные автором этимологические решения и реконструкции семантической истории слов семинаристского и чиновничьего жаргона XIX в.: сморозить, аксиосы и др. 
Наряду с оригинальными этимологическими толкованиями заслугой И.Г. Добродомова является детализация и дополнительная аргументация предложенных ранее этимологических решений на базе тщательной реконструкции исторического «движения» слова в истории русского языка и его связей с другими языками и как преемника, и как донора. См. разработки толкований слов книга, олух, кметь, Коломна и др.

Этимологические толкования, реконструкция структурных и семантических преобразований исходных слов-источников заимствований, разработанные И.Г. Добродомовым для многих из перечисленных выше русских лексем (таких, как абитуриент, бурбонка, карман, лошадь, сабля, хлябь), убедительно вошли в число достижений отечественной этимологической мысли.

Труды И.Г. Добродомова являются прекрасной панорамой диалектики этимологической аргументации и разновекторности этимологического поиска.

\section{Литература}

Добродомов 1964 - Добродомов И.Г. Из половецкой ономастики. Таз Боняк // Известия АН СССР. Серия литературы и языка. - T. XXIII. — Вып. 3. - 1964. С. 256-258.

Добродомов 1966 - Добродомов И.Г. О методах исследования древнейших тюркизмов в составе русского словаря (К истории слова жемчуг) // Изв. АН СССР. Сер. лит. и яз. Т. XXV. — Вып. 1. - 1966. — с. 57-64.

Добродомов 1967 - Добродомов И.Г. Слова-путешественники (Магазин. Казна. Казначей) // Русская речь. - № 1. - 1967.

Добродомов 1968а - Добродомов И.Г. Дрофа - дудак. Этимологические заметки // Русская речь. — №4. - 1968. - с. 100-104.

Добродомов 19686 - Добродомов И.Г. Этимологическая страничка. Шлык, жилет // Русский язык в школе. - 1968. - №3. - с. 90.

Добродомов 1969 - Добродомов И. Г. Из булгарского вклада в славянских языках I //Этимология 1967. — М., 1969.

Добродомов 1970а - Добродомов И.Г. Веселая этимология. Таракан в этимологическом аспекте // Русская речь. - № 6. - 1970. - с. 97-100.

Добродомов $1970 б$ - Добродомов И.Г. К этимологии марийского названия лошади // Советское финноугроведение. - Т. VI. — №4. — Таллин, 1970. — c. 253-254.

Добродомов 1970в - Добродомов И.Г. Камасы и гамаши // Русская речь. №3. - 1970. - с. 89, 114.

Добродомов 1971a - Добродомов И.Г. Бродячие слова // Русская речь. 1971. — № 1. — с. 129-137.

Добродомов 19716 - Добродомов И.Г. Из булгарского вклада в славянских языках II // Этимология 1968. - М., 1971.

Добродомов 1971в - Добродомов И.Г. Книга // Русская речь. - 1971. №5. - с. 83-91.

Добродомов 1971г - Добродомов И.Г. Янтарь // Русская речь. - №4. 1971. — c. 138-142. 
Добродомов 1972а - Добродомов И.Г. Из булгарского вклада в славянских языках III // Этимология 1970. - М. 1972. — c. 103-115.

Добродомов $1972 б$ - Добродомов И.Г. Новая одежда старых слов // Русская речь. - № 2. - 1972. - С. 67-72.

Добродомов 1973а - Добродомов И.Г. К этимологии слова вор // Диалекты и топонимия Поволжья. Вып. 2. - Чебоксары, 1973. — с. 75-86.

Добродомов 19736 - Добродомов И.Г. Тьмуторокань и Тамань // Русская речь. — № 5. - 1973. — с. 129-133.

Добродомов 1974а - Добродомов И.Г. Колчан // Русская речь. - №4. 1974. — с. 115-120.

Добродомов 19746 - Добродомов И.Г. Пути проникновения булгарских элементов в славянские языки // Тюркизмы в восточнославянских языках. - M., 1974. - с. $26-43$.

Добродомов 1975 - Добродомов И.Г. Проблемы филологической достоверности слова в словарях // Проблемы славянской исторической лексикологии и лексикографии. - Вып. 4. - 1975. - с. 29.

Добродомов 1976 - Добродомов И.Г. Загадочная параллель: бур (бор) орхонских рунических надписей и боръ (*бъръ) «Повести временных лет» // Turcologica. К семидесятилетию академика А. Н. Кононова. - Л., 1976. с. 241-246.

Добродомов 1977 - Добродомов И. Г. Жудь и жуть // Русская речь. — №3. 1977. — с. $157-160$.

Добродомов 1978 - Добродомов И.Г. К изучению лексики «Русской Правды» (nорть 'топор' и порть 'одежда') // Восточнославянское и общее языкознание. M. 1978. - c. 133-136.

Добродомов 1980 - Добродомов И.Г. Ещё о слове балаган // Русская речь. № 1. - 1980. - c. 141-144.

Добродомов 1981 - Добродомов И.Г. Об аланизмах в русском языке // Oсетинская филология. Межвузовский сборник статей. Вып. 2. - Орджоникидзе, 1981. — с. 37-42.

Добродомов 1983 - Добродомов И.Г. К этимологии церковнославянского хлеАбь (хлАбь) // Этимология 1981. - М., 1983. — с. 29-35.

Добродомов 1984 - Добродомов И.Г. Об одной хантыйско-эвенкийской параллели и ее происхождении // Советское финноугроведение. - Т. ХX. - № 3. Таллин, 1984. - с. 195-198.

Добродомов 1985a - Добродомов И. Г. Ещё раз о славянских вариантах *sabja, *shabja // Этимология 1983. — М., 1985. — c. 88-92.

Добродомов 19856 - Добродомов И.Г. К этимологии мордовского названия берёзы // 6 Международный конгресс фино-угроведов в Сыктывкаре (июль 1985 г.).

Добродомов 1987a - Добродомов И. Г. Потасовка // Русская речь. - № 1. 1987. - с. 133-136.

Добродомов 19876 - Добродомов И.Г. Существовало ли на Волге слово фурстовина? // Двуязычие и контрастивная грамматика. - Чебоксары, 1987. — С. 18 25 . 
Добродомов 1987в - Добродомов И.Г. Читая Чехова и словари... (Фендрик, чемерица, мантифолия) // Диалектное и просторечное слово в диахронии и синхронии. - Вологда, 1987. — с. 110-117.

Добродомов 1988a - Добродомов И.Г. Люстра и ее «конкурент» // Русская речь. - №3. - 1988. - с. 133-137.

Добродомов 19886 - Добродомов И.Г. О происхождении слова трещотка // Русский язык в школе. — № 1. - 1988. — c. 90-92.

Добродомов 1988в - Добродомов И.Г. Этика и этикет // Русская речь. №4. - 1988. - с. 127-130.

Добродомов 1989 - Добродомов И.Г. К истории глагола транжирить // Этимология 1986-1987. - М., 1989. — с. 194-200.

Добродомов 1991 - Добродомов И.Г. Еще раз о кузькиной матери // Русская речь. — №2. - 1991. — с. 134-138.

Добродомов 1993a - Добродомов И. Г. Город Коломна (топонимический этюд с источниковедческими экскурсами) // Топонимия России. - М., 1993. - c. 55-73.

Добродомов 19936 - Добродомов И.Г. Об одном алано-буртасском имени в эпитафиях волжских булгар XIV века // Ономастика и эпиграфика средневековой Восточной Европы и Византии. — М., 1993. - c. 130-150.

Добродомов 1997 - Добродомов И.Г. Еще раз: куряне сведоми къмети «Слова о полку Игореве» // Вопросы языкознания. — № 3. - 1997. — с. 53-62.

Добродомов 1998 - Добродомов И.Г. Немые Кизляры (из комментария к «Бахчисарайскому фонтану») // Philologica. - 1998. — Vol. 5. — № 11/12. - c. 133-137.

Добродомов 2002 - Добродомов И.Г. Проблема филологической достоверности материала в исторических словарях // Древняя Русь. Вопросы медиевистики. —№ 4 (10). - М., 2002. - С. 5-20.

Добродомов 2003a - Добродомов И.Г. Еще раз об этимологии слова олух // Этимология 2000-2002. - М., 2003. - с. 120-126.

Добродомов 20036 - Добродомов И.Г. Чем грозила и грозит «реформа» орфографии // Русский вестник. - 2003. - 27 июля.

Добродомов 2008 - Добродомов И.Г. Древнерусские гапаксы и этимологические соображения // Проблемы филологии народов Поволжья. вып. 2. - М.-Ярославль, 2008. - с. 10-11.

Добродомов 2009 - Добродомов И.Г. Иллюзорные галлицизмы офенского происхождения: шаромыга, шармак // Русистика. Прошлое и настоящее национального языка. Сб.статей, посвященный 70-летию профессора Б. И. Осипова. Омск, 2009. - С. 188-204.

Добродомов 2010 - Добродомов И. Г. Об одном призрачном слове у В. И. Даля (вклад Ахмеда Ибн Фадлана и О.И. Сенковского в русскую лексику) // Владимир Даль в счастливом доме на Пресне. - М.: Academia, 2010. — c. 99-108.

Добродомов 2011a - Добродомов И.Г. Арготические глаголы с маскировочным суф. -ма- // «И нежный вкус родимой речи...»: сб. научных трудов, посв. юбилею доктора филол. наук проф. Л. А. Климковой. - Арзамас, 2011. — с. $183-$ 188. 
Добродомов 20116 - Добродомов И.Г. Из мерянского вклада в русское слово-

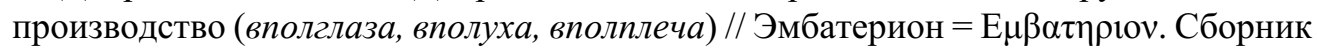
статей по искусствознанию, филологии, истории. К 70-летию В. П. Яйленко. - М., 2011. - c. 214-218.

Добродомов 2013а - Добродомов И.Г. Батрак, малай, баранчук // Российская тюркология. — № 1(8). — М.; Казань, 2013. — c. 76-81.

Добродомов 20136 - Добродомов И.Г. Этимологические заметки о русском семинарском жаргоне: взъефантулить, сморозить, аксиосы // Slověne. Internatonal Journal of Slavic Studies. - Vol. 2. — № 2. - 2013. - c. 143-171.

Добродомов 2014a - Добродомов И.Г. Источниковедение и история слова // Герменевтика древнерусской литературы. - Вып. 16-17. - М., 2014. - С. 748781.

Добродомов 2014б - Добродомов И. Г. Шибболет: библеизм или галлицизм? // Вестник Литературного института им. А. М. Горького. — 2014. - №2.

Добродомов, Камчатнов 2014 - Добродомов, Камчатнов А. М. Дериватологические признаки // Древняя Русь. Вопросы медиевистики. - №3(57). — 2014. c. $13-20$.

Добродомов, Шаповал 2005 - Добродомов И.Г. Шаповал В.В. О призрачных словах у лексикографов // Palaeoslavica. International Journal for the Study of Slavic Medieval Literature, History, Language and Ethnology. - Vol. XIII. - No. 1. Cambridge - Massachusetts, 2005. - p. 331-337.

Добродомов, Эккерт 1986 - Добродомов И.Г., Эккерт Р. Значение изучения фразеологизмов в тексте (по поводу фразеологизмов держать в чёрном теле; держать в ежовых рукавииах) // ZfS1 - Bd. 31. - №3. - Berlin, 1986. - S. 425-436.

\section{T. V. Goryacheva, O.M. Sergeeva}

Vinogradov Russian Language Institute of the Russian Academy of Sciences

(Russia, Moscow)

etymol@mail.ru

\section{Review of: DOBRODOMOV IGOR' GEORGIEVICH. IZBRANNYE TRUDY PO ETIMOLOGII I LEKSIKOLOGII [SELECTED WORKS ON ETYMOLOGY AND LEXICOLOGY]. - Moscow: MPGU, 2015. — 460 p. — ISBN 978-5-4263-0284-6}

The review presents the research work Dobrodomov, Igor' Georgievich. Izbrannye trudy po etimologii i leksikologii, published in late 2015.

Keywords: vocabulary, word, idiom, appellative, placename, borrowing, slang word, dialectism. 


\section{References}

Dobrodomov 1964 - Dobrodomov I. G. Iz polovetskoi onomastiki. Taz Bonyak [From Cuman Onomastics. Taz Bonyak]. Izvestiya AN SSSR [Bulletin of the Academy of Sciences of the USSR]. Series Literature and Language. Vol. XXIII. Issue 3. 1964. P. 256-258.

Dobrodomov 1966 - Dobrodomov I. G. O metodakh issledovaniya drevneishikh tyurkizmov $v$ sostave russkogo slovarya (K istorii slova zhemchug) [On the Methods of Studying the Earliest Turkisms in the Russian Vocabulary (To the History of Russ. zhemchug 'pearl')]. Izvestiya AN SSSR [Bulletin of the Academy of Sciences of the USSR]. Series Literature and Language. Vol. XXV. Issue 1. 1966. p. 57-64.

Dobrodomov 1967 - Dobrodomov I. G. Slova-puteshestvenniki (Magazin. Kazna. Kaznachei) [Wandering Words. Magazin 'store'. Kazna 'treasury'. Kaznachei 'treasurer']. Russkaya rech' [Russian Speech]. No.1. 1967.

Dobrodomov 1968a - Dobrodomov I. G. Drofa — dudak. Etimologicheskie zametki [Drofa - dudak 'bustard'. Etymological Notes]. Russkaya rech' [Russian Speech]. No. 4. 1968. p. 100-104.

Dobrodomov 1968b - Dobrodomov I. G. Etimologicheskaya stranichka. Shlyk, zhilet [Etymological page. Russ. shlyk 'type of headwear', zhilet 'vest']. Russkii yazyk $v$ shkole [Russian Language at School]. 1968. No. 3. p. 90.

Dobrodomov 1969 - Dobrodomov I. G. Iz bulgarskogo vklada v slavyanskikh yazykakh I [From Bulgar Contributions to Slavic Vocabulary I]. Etimologiya [Etymology] 1967. Moscow, 1969.

Dobrodomov 1970a - Dobrodomov I. G. Veselaya etimologiya. Tarakan v etimologicheskom aspekte [Fun Etymology. Tarakan 'cockroach' in Its Etymological Aspect]. Russkaya rech' [Russian Speech]. No. 6. 1970. p. 97-100.

Dobrodomov 1970b - Dobrodomov I. G. K etimologii mariiskogo nazvaniya loshadi [To the Etymology of the Mari Word for Horse]. Sovetskoe finnougrovedenie [Soviet Finno-Ugric Studies]. vol. VI. No. 4. Tallin, 1970. p. 253-254.

Dobrodomov 1970v — Dobrodomov I. G. Kamasy $i$ gamashi [Kamasy 'animal hides used for making hand- and footwear' and gamashi 'spats']. Russkaya rech' [Russian Speech]. No. 3. 1970. p. 89, 114.

Dobrodomov 1971a - Dobrodomov I.G. Brodyachie slova [Wandering Words]. Russkaya rech' [Russian Speech]. 1971. No. 1. p. 129-137.

Dobrodomov 1971b - Dobrodomov I. G. Iz bulgarskogo vklada v slavyanskikh yazykakh II [From Bulgar Contributions to Slavic Vocabulary II]. Etimologiya [Etymology] 1968. Moscow, 1971.

Dobrodomov 1971v — Dobrodomov I. G. Kniga [Russ. kniga 'book']. Russkaya rech' [Russian Speech]. 1971. No. 5. p. 83-91.

Dobrodomov 1971g — Dobrodomov I. G. Yantar' [Russ. yantar' 'amber']. Russkaya rech' [Russian Speech]. No. 4. 1971. p. 138-142.

Dobrodomov 1972a - Dobrodomov I. G. Iz bulgarskogo vklada v slavyanskikh yazykakh III [From Bulgar Contributions to Slavic Vocabulary III]. Etimologiya 1970. Moscow, 1972. p. 103-115. 
Dobrodomov 1972b - Dobrodomov I. G. Novaya odezhda starykh slov [New Garments for Old Words]. Russkaya rech' [Russian Speech]. No. 2. 1972. P. 67-72.

Dobrodomov 1973a - Dobrodomov I. G. K etimologii slova vor [To the Etymology of Russ. vor 'thief']. Dialekty i toponimiya Povolzh'ya [Dialects and Toponymy of the Volga Region]. Issue. 2. Cheboksary, 1973. p. 75-86.

Dobrodomov 1973b - Dobrodomov I. G. T'mutorokan' $i$ Taman' [T'mutorokan' and Taman', placenames]. Russkaya rech' [Russian Speech]. No. 5. 1973. p. 129133.

Dobrodomov 1974a — Dobrodomov I. G. Kolchan [Russ. kolchan 'quiver']. Russkaya rech' [Russian Speech]. No. 4. 1974. p. 115-120.

Dobrodomov 1974b - Dobrodomov I. G. Puti proniknoveniya bulgarskikh elementov v slavyanskie yazyki [Paths of Introduction of Bulgar Elements into Slavic Languages]. Tyurkizmy $v$ vostochnoslavyanskikh yazykakh [Turkisms in East Slavic Languages]. Moscow, 1974. p. 26-43.

Dobrodomov 1975 - Dobrodomov I. G. Problemy filologicheskoi dostovernosti slova $v$ slovaryakh [Problems of Philological Veracity of Vocabulary Items]. Problemy slavyanskoi istoricheskoi leksikologii i leksikografii [Issues in Slavic Historical Lexicology and Lexicography]. Issue 4. 1975. p. 29.

Dobrodomov 1976 - Dobrodomov I. G. Zagadochnaya parallel': bur (bor) orkhonskikh runicheskikh nadpisei $i$ borъ (*bъrъ) «Povesti vremennykh let» [An Enigmatic Parallel: bur (bor) of Orkhon Runic Inscriptions and borz (*brrb) of the Russian Primary Chronicle]. Turcologica [Turkic Studies]. On the Occasion of Academician A.N Kononov's $70^{\text {th }}$ Birthday. - Leningrad, 1976. p. 241-246.

Dobrodomov 1977 - Dobrodomov I. G. Zhud' $i$ zhut' ['horror, terror']. Russkaya rech' [Russian Speech]. No. 3. 1977. p. 157-160.

Dobrodomov 1978 - Dobrodomov I.G. Kizucheniyu leksiki «Russkoi Pravdy» (port' 'topor'» $i$ port' 'odezhda') [To the Studies of «Russkaia Pravda» Vocabulary: port' 'axe' and port' 'clothing item']. Vostochnoslavyanskoe i obshchee yazykoznanie [East Slavic and General Linguistics]. Moscow, 1978. - p. 133-136.

Dobrodomov 1980 - Dobrodomov I. G. Eshche o slove balagan [Once more on Russ. balagan 'fairground show; booth wherein such show is performed; foolery']. Russkaya rech' [Russian Speech]. No. 1. 1980. p. 141-144.

Dobrodomov 1981 - Dobrodomov I. G. Ob alanizmakh v russkom yazyke [On Alanisms in Russian]. Osetinskaya filologiya [Ossetian Philology]. Intercollegiate collected papers. Issue 2. Ordzhonikidze, 1981. p. 37-42.

Dobrodomov 1983 - Dobrodomov I. G. K etimologii tserkovnoslavyanskogo khliab' (khlęb') [On the etymology of Church Slavonic khliab' (khlęb')]. Etimologiya [Etymology] 1981. Moscow, 1983. p. 29-35.

Dobrodomov 1984 - Dobrodomov I.G. Ob odnoi khantyisko-evenkiiskoi paralleli i ee proiskhozhdenii [On A Khanty-Evenki Parallel and Its Origin]. Sovetskoe finnougrovedenie [Soviet finno-Ugric Studies]. Vol. 20. No. 3. Tallin, 1984. p. 195-198.

Dobrodomov 1985a - Dobrodomov I. G. Eshche raz o slavyanskikh variantakh *sabja, *shabja [Once More on Slavic Variants *sabja, *shabja]. Etimologiya [Etymology] 1983. Moscow, 1985. p. 88-92. 
Dobrodomov 1985b - Dobrodomov I. G. K etimologii mordovskogo nazvaniya berezy [To the Etymology of the Mordovian word for 'birch']. $6^{\text {th }}$ International Congress of Finno-Ugric Studies in Syktyvkar (July 1985).

Dobrodomov 1987a — Dobrodomov I. G. Potasovka [Potasovka 'brawl']. Russkaya

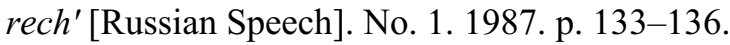

Dobrodomov 1987b - Dobrodomov I. G. Sushchestvovalo li na Volge slovo furstovina? [Did the word furstovina 'stormy weather' exist on the Volga?]. Dvuyazychie $i$ kontrastivnaya grammatika [Bilingualism and Contrastive Grammar]. Cheboksary, 1987. P. 18-25.

Dobrodomov 1987v - Dobrodomov I. G. Chitaya Chekhova i slovari... (Fendrik, chemeritsa, mantifoliya) [Reading Chekhov and Dictionaries: Fendrik' 'a military rank; coxcomb, fopling', chemeritsa 'plant name', mantifoliya 'exalted speech']. Dialektnoe i prostorechnoe slovo v diakhronii i sinkhronii [Dialectal and Colloquial Word in Diachrony and Synchrony]. Vologda, 1987. p. 110-117.

Dobrodomov 1988a — Dobrodomov I. G. Lyustra i ee «konkurent» [Chandelier and its «competition»]. Russkaya rech' [Russian Speech]. No. 3. 1988. p. 133-137.

Dobrodomov 1988b - Dobrodomov I.G. O proiskhozhdenii slova treshchotka [On the Origin of treshchotka 'rattle']. Russkii yazyk v shkole [Russian Language at School]. No. 1. 1988. p. $90-92$.

Dobrodomov 1988v — Dobrodomov I.G. Etika i etiket [Ethics and Etiquette]. Russkaya rech' [Russian Speech]. No. 4. 1988. p. 127-130.

Dobrodomov 1989 - Dobrodomov I. G. K istorii glagola tranzhirit' [To the History of tranzhirit' 'to spend uncontrollably, waste (money)']. Etimologiya [Etymology] 19861987. Moscow, 1989. p. 194-200.

Dobrodomov 1991 - Dobrodomov I.G. Eshche raz o kuz'kinoi materi [Once more on kuzkina mat']. Russkaya rech' [Russian Speech]. No. 2. 1991. p. 134-138.

Dobrodomov 1993a - Dobrodomov I. G. Gorod Kolomna (toponimicheskii etyud s istochnikovedcheskimi ekskursami) [The town Kolomna: an Essay in Toponymy with Source Study Excursi]. Toponimiya Rossii [Toponomastics of Russia]. Moscow, 1993. p. 55-73.

Dobrodomov 1993b - Dobrodomov I. G. Ob odnom alano-burtasskom imeni v epitafiyakh volzhskikh bulgar XIV veka [On an Alanian-Burtas Name in Volga Bulgar Epitaphies of the $14^{\text {th }}$ Century]. Onomastika i epigrafika srednevekovoi Vostochnoi Evropy $i$ Vizantii [Onomastics and Epigraphy of the Medieval Eastern Europe and Byzantium]. Moscow, 1993. p. 130-150.

Dobrodomov 1997 - Dobrodomov I. G. Eshche raz: kur’ane svedomi kъmeti «Slova o polku Igoreve» [Once More: 'kur'ane svedomi kbmeti' of the Tale of Igor's Campaign]. Voprosy yazykoznaniya [Issues in Linguistics]. No. 3. 1997. p. 53-62.

Dobrodomov 1998 — Dobrodomov I. G. Nemye Kizlyary (iz kommentariya k «Bakhchisaraiskomu fontanu») [The Mute Kizlyary: from a commentary on A. Pushkin's The Fountain of Bakhchisaray]. Philologica. 1998. Vol. 5. No. 11/12. p. 133-137.

Dobrodomov 2002 - Dobrodomov I. G. Problema filologicheskoi dostovernosti materiala $v$ istoricheskikh slovaryakh [The Problem of Philological Veracity of Historical 
Dictionary Data]. Drevnyaya Rus'. Voprosy medievistiki [Old Rus'. Issues in Medieval Studies]. No. 4 (10). Moscow, 2002. P. 5-20.

Dobrodomov 2003a - Dobrodomov I.G. Eshche raz ob etimologii slova olukh [Once More on the Etymology of olukh 'foolish individual']. Etimologiya [Etymology] 2000-2002. Moscow, 2003. p. 120-126.

Dobrodomov 2003b — Dobrodomov I. G. Chem grozila i grozit «reforma» orfografii [What was and what is threatening about the «reform» of Russian orthography]. Russkii vestnik [Russian Messenger] 2003. July 27.

Dobrodomov 2008 - Dobrodomov I. G. Drevnerusskie gapaksy i etimologicheskie soobrazheniya [Old Russian Hapaxes and Etymological Considerations]. Problemy filologii narodov Povolzh'ya [Issues in Philological Studies of Volga Region Peoples' Heritage]. Issue 2. Moscow-Yaroslavl', 2008. p. 10-11.

Dobrodomov 2009 - Dobrodomov I. G. Illyuzornye gallitsizmy ofenskogo proiskhozhdeniya: sharomyga, sharmak [Delusory Gallicisms of Trade Slang Origin: sharomyga 'parasite', sharmak 'option of obtaining sth. for free']. Rusistika. Proshloe i nastoyashchee natsional'nogo yazyka [Russian Studies. The Past and the Present of the National Language]. Collected papers presented on the Occasion of Prof. B. I. Osipov's $70^{\text {th }}$ Birtday. Omsk, 2009. P. 188-204.

Dobrodomov 2010 - Dobrodomov I. G. Ob odnom prizrachnom slove u V.I. Dalya (vklad Akhmeda Ibn Fadlana i O. I. Senkovskogo v russkuyu leksiku) [On a Phantom Word in Vladimir Dal's Dictionary: Contribution by Ahmad ibn Fadlan and Osip Senkovsky to Russian Vocabulary]. Vladimir Dal'v schastlivom dome na Presne [Vladimir Dal' at a 'happy' house on the Presnya]. Moscow: Academia, 2010. p. 99-108.

Dobrodomov 2011a — Dobrodomov I.G. Argoticheskie glagoly s maskirovochnym suf. -ma- [Slang Verbs with a Disguise Suffix -ma-]. "I nezhnyi vkus rodimoi rechi...» ['...And a Sweet Taste of Native Speech']: collected papers on the occasion of Prof. L. A. Klimkova' s birthday. Arzamas, 2011. p. 183-188.

Dobrodomov 2011b — Dobrodomov I. G. Iz meryanskogo vklada v russkoe slovoproizvodstvo (vpolglaza, vpolukha, vpolplecha) [From the Merya Contribution to Russian Word Derivation]. Embaterion $=E \mu \beta \alpha \tau \eta \rho ı v$. Collected Papers in Art Studies, Philology, History. On the Occasion of V.P. Yailenko's $70^{\text {th }}$ Birthday. Moscow, 2011. p. 214218.

Dobrodomov 2013a - Dobrodomov I. G. Batrak, malai, baranchuk [Batrak' worker for hire', malai 'boy; worker', baranchuk 'boy, adolescent']. Rossiiskaya tyurkologiya [Russian Turcology]. No. 1(8). Moscow; Kazan', 2013. p. 76-81.

Dobrodomov 2013b - Dobrodomov I.G. Etimologicheskie zametki o russkom seminarskom zhargone: vz'efantulit', smorozit', aksiosy [Etymological Notes on Russian Theological College Student Slang: $v z$ 'efantulit' 'to subject to harsh (verbal) punishment'; smorozit' 'to (carelessly) say (sth. inappropriate)', aksiosy 'hair']. Slověne. Internatonal Journal of Slavic Studies. Vol. 2. No. 2. 2013. p. 143-171.

Dobrodomov 2014a - Dobrodomov I. G. Istochnikovedenie i istoriya slova [Source Studies and History of Word]. Germenevtika drevnerusskoi literatury [Hermeneutics of Old Russian Literature]. - Issue 16-17. — Moscow, 2014. — P. 748-781. 
Dobrodomov 2014b — Dobrodomov I. G. Shibbolet: bibleizm ili gallitsizm? [Shibbolet 'notable speech marker': a Bibleism or a Gallicism?]. Vestnik Literaturnogo instituta im. A. O. Gor'kogo [Bulletin of A. M. Gorky Institute of Literature]. 2014. No. 2.

Dobrodomov, Kamchatnov 2014 - Dobrodomov I. G., Kamchatnov A. M. Derivatologicheskie priznaki [Derivatological Signs]. Drevnyaya Rus'. Voprosy medievistiki [Old Rus'. Issues in Medieval Studies]. No. 3(57). 2014. p. 13-20.

Dobrodomov, Shapoval 2005 - Dobrodomov I. G., Shapoval V.V. O prizrachnykh slovakh u leksikografov [On Phantom Words in Lexicographers' Corpora]. Palaeoslavica. International Journal for the Study of Slavic Medieval Literature, History, Language and Ethnology. Vol. XIII. No. 1. Cambridge Massachusetts, 2005. p. 331-337.

Dobrodomov, Ekkert 1986 - Dobrodomov I. G., Ekkert R. Znachenie izucheniya frazeologizmov v tekste (po povodu frazeologizmov derzhat' v chernom tele; derzhat' v ezhovykh rukavitsakh) [The Significance of Studying Phraseological Units in Text (regarding the idioms derzhat' $v$ chernom tele; derzhat' $v$ ezhovykh rukavitsakh 'keep s.o. in strict submission, force restrictions onto s.o.']. ZfSl, Bd. 31. No. 3. Berlin, 1986. P. 425-436. 